\title{
Economic Costs of Abdominal Obesity
}

\author{
Betina Højgaard $^{\mathrm{a}} \quad$ Kim Rose Olsen $^{\mathrm{a}} \quad$ Jes Søgaard $^{\mathrm{a}} \quad$ Thorkild I.A. Sørensen $^{\mathrm{b}}$ \\ Dorte Gyrd-Hansen ${ }^{\mathrm{a}, \mathrm{c}}$ \\ ${ }^{a}$ Danish Institute for Health Services Research, \\ b Institute of Preventive Medicine, Copenhagen University Hospital, Centre for Health and Society, Copenhagen, \\ ${ }^{\mathrm{c}}$ Institute of Public Health, University of Southern Denmark, Denmark
}

\section{Key Words}

Obesity · Prevention · Health care costs .

Waist circumference

\section{Summary}

Background: To examine the relationship between waist circumference and future health care costs across a broad range of waist circumference values based on individual level data. Method: A prospective cohort of 31,840 subjects aged 50-64 years at baseline had health status, lifestyle and socio-economic aspects assessed at entry. Individual data on health care consumption and associated costs were extracted from registers for the subsequent 7 years. Participants were stratified by presence of chronic disease at entry. Results: Increased waist circumference at baseline was associated with higher future health care costs. For increased and substantially increased waist circumference health care costs rise at a rate of $1.25 \%$ in women and $2.08 \%$ in men, per added centimetre above normal waistline. Thus, as an example, a woman with a waistline of $95 \mathrm{~cm}$ and without co-morbidities can be expected to incur an added future cost of approximately USD 397.- per annum compared to a woman in the normal waist circumference group, corresponding to $22 \%$ higher health care costs. Conclusions: Future health care costs are higher for persons who have an increased waist circumference, which suggests that there may be a potential for significant resource savings through prevention of abdominal obesity.

\section{Introduction}

The prevalence of overweight and obesity is increasing worldwide, and is therefore a growing cause for concern [1]. Largescale epidemiological cohort studies have shown that obesity (as assessed by body mass index (BMI) or waist circumference (WC)) is a prominent risk factor for a number of major diseases including coronary heart disease, diabetes mellitus, osteoarthritis of the knee, several types of cancer, gallbladder disease, sleep apnoea, hypertension and stroke [1,2]. The increased risk of morbidity also leads to increased risk of premature mortality $[1,2]$.

Many economic studies report that the increased obesity-related morbidity and mortality is associated with excess health care costs [3-28]. Many of these estimates are based on population attributable risk (PAR) [7, 9, 14, 16, 18-20, 27, 29-31]. PAR measure the proportions of cases of a given disease (e.g. type II diabetes) that is due to a risk factor of interest (e.g. obesity). Total attributable health care costs of obesity is estimated as the sum of products of disease-specific PARs and health care costs. The PAR method is an indirect way of estimating the health care costs of obesity. A more accurate method is to estimate the health care cost directly by use of a cohort design. Only a few studies have directly examined the relationship between obesity and health care costs based on a prospective/retrospective cohort design $[3,5,6,11,15,17$, 23-25,29-31]. All but four of these studies apply self-reported heights and weights $[11,24,29,31]$.

Almost all economic studies in the literature are based on BMI as a widely accepted measure of obesity, well correlated with total body fat. However, a growing body of literature has documented that the size of the various adipose tissue depots is of importance, and especially the intraabdominal visceral fat is associated with serious health problems [32-34]. Studies have shown that WC correlates reasonably well with visceral

\begin{tabular}{ll}
\hline KARGER & @ 2008 S. Karger GmbH, Freiburg \\
Fax +49 7614520714 & Accessible online at: \\
$\begin{array}{l}\text { E-mail Information@Karger.de } \\
\text { www.karger.com }\end{array}$ & www.karger.com/ofa
\end{tabular}

Betina Højgaard, M.S. (econ) 
fat areas and that the correlation is higher than for BMI [35, 36]. It has been shown that WC more precisely identifies highrisk individuals by pinpointing those with a high body fat content and an increased intraabdominal accumulation of fat [37]. This result is supported by a study based on the same data as in this article, which demonstrates that $\mathrm{WC}$ is a better predictor of future health care costs than BMI [38].

Two health economic studies $[10,12]$ found increased costs associated with increased WC, but limitations of their study design makes it difficult to derive generally applicable estimates of the health care costs. One study only included a small and unrepresentative sample of 424 persons with a relatively low socio-economic status [10]. The other study was based on a more limited cost study, which only included hospital costs [12].

Numerous studies have shown that WC is a strong predictor of obesity-related morbidity and mortality [39]. However, knowledge about the association between WC and health care costs is lacking. Understanding variations in health care expenditures across a full range of WC values contributes to establishing rational grounds for targeting preventive and weight-reducing interventions. The present study examines the relationship between WC and future health care costs across a broad range of waist circumference values based on individual level data.

\section{Material and Methods}

The analysis is based on a prospective cohort study in which a selected sample of the general Danish adult population was invited to a baseline health status screening in 1996-1997. Health status, lifestyle and socio-economic variables were assessed at baseline while individual data on health care consumption and associated costs were extracted from registers for the subsequent 7 years (1996/1997 through 2003/2004).

\section{Population}

The baseline data were derived from the Danish prospective cohort study Diet, Cancer and Health (DCH) [40]. The study population consisted of individuals born in Denmark, who were aged 50-64 years at baseline, residing in the greater Copenhagen or Aarhus areas and did not have any records of cancer in the Danish Cancer register at the time of selection. The participants provided questionnaire data on diet and lifestyle. Anthropometric measurements, blood pressure and biological material were collected by trained staff. Details of the cohort study have been described previously [40].

The baseline survey was conducted between December 1993 and May 1997, a total of 160,725 individuals were invited to participate in the DCH study. Of these a total of 57,055 visited a study clinic in the study period [40]. Owing to constraints on the accessibility of uniform cost data (reporting procedures varied in the previous time period), it was necessary to restrict inclusion in the present cost analysis to individuals visiting the study clinic in the period January 1996 to May $1997(n=33,083)$. Of this sample a number of participants were excluded owing to missing data. A total of 31,840 participants $(97 \%)$ of the qualified individuals were eligible for analysis: 15,344 men and 16,506 women.

\section{Variables from $\mathrm{DCH}$}

\section{Anthropometric Measures}

Height was measured with participants standing without shoes and was recorded to the nearest half centimetre. Weight was measured by a digital scale and recorded to the nearest 100 grams. The participants wore light clothing or underwear at the weighing. BMI was calculated as weight in kilograms divided by height in metres squared. $W C$ was measured with a tape measure at the narrow part of the torso between the lowest rib and the level of the iliac crests (the natural waist) or, in case of an indeterminable waist narrowing, halfway between the lower rib and the iliac crest and was recorded to the nearest half centimetre.

The World Health Organisation's (WHO) definition of obesity according to WC was used in this study. A woman was defined as having increased WC if WC was $\geq 80 \mathrm{~cm}$ and substantially increased WC if WC was $\geq 88 \mathrm{~cm}$. For men the respective cut-off points were 94 and $102 \mathrm{~cm} \mathrm{[1].} \mathrm{Women} \mathrm{with}$ WC less than $80 \mathrm{~cm}$, and men with WC less than $94 \mathrm{~cm}$ were considered as having a normal waistline. The range for normal BMI was 18.50-24.99 $\mathrm{kg} / \mathrm{m}^{2}$. If BMI was $<18.5 \mathrm{~kg} / \mathrm{m}^{2}$, the person was defined as underweight while a person was overweight if BMI was $25 \mathrm{~kg} / \mathrm{m}^{2}$ and obese if BMI was $30 \mathrm{~kg} / \mathrm{m}^{2}[1]$.

\section{Co-Morbidity Measures}

Co-morbidity variables were based on the participant's information on medical history and the results of the physical examination, which included blood pressure measurement after limited rest.

Participants were categorised according to co-morbidity as follows. $\mathrm{Hy}$ pertension: A person was defined as having hypertension if (s)he reported this in the questionnaire or if the physical examination showed a systolic blood pressure $140 \mathrm{~mm} \mathrm{Hg}$ or a diastolic blood pressure $90 \mathrm{~mm} \mathrm{Hg}$. A person was included in the Diabetes or in the Cardiovascular disease (CVD) group if (s)he reported that (s)he had diabetes or previously had CVD. In this study CVD includes angina pectoris, myocardial infarction and stroke.

\section{Lifestyle Factors}

Lifestyle factors were obtained through the lifestyle questionnaire completed at the study clinics at enrolment. Data on smoking were based on self-reported smoking status (current, past or never) and current tobacco consumption (g/day). In the present analyses, the respondents were classified as heavy smokers if they smoked $15 \mathrm{~g} /$ day or more. Physical activity was self-reported in the form of a categorical variable, indicating whether the individual was engaged in sports activities (yes or no).

\section{Education, Income, Emigration and Death}

All residents of Denmark have a unique 10-digit individual identification number (CPR numbers), which makes it possible to establish a highly accurate linkage between various registers at the individual level. Information about emigration and death in the follow-up period was collected from Statistic Denmark, as was information on respondents' highest level of education at baseline. Income was calculated as the gross household income (obtained from Statistic Denmark) in the year prior to the baseline year divided by the number of adults in the household.

\section{Health Care Costs}

The costs analysed were the direct health care costs, including patients' copayment on specialist services and medication irrespective of disease diagnosis. Indirect costs, such as those associated with lost productivity, were not evaluated. The health care system in Denmark is predominantly publicly financed by income and other taxes, and the private health care sector plays only a minor role. 
Table 1. Baseline characteristics of study participants by WC

\begin{tabular}{|c|c|c|c|c|}
\hline \multirow[t]{2}{*}{ Characteristic } & \multicolumn{3}{|c|}{ Female study participants } & \multirow[t]{2}{*}{$\mathrm{p}$ value } \\
\hline & $\begin{array}{l}\text { normal WC } \\
(<80 \mathrm{~cm})\end{array}$ & $\begin{array}{l}\text { increased WC } \\
(80-87.99 \mathrm{~cm})\end{array}$ & $\begin{array}{l}\text { substantially increased WC } \\
(\geq 88 \mathrm{~cm})\end{array}$ & \\
\hline Number & 7,667 & 4,323 & 4,516 & \\
\hline $\mathrm{WC}, \mathrm{cm}$ & $73.4 \pm 4.1$ & $83.3 \pm 2.3$ & $96.7 \pm 8.0$ & \\
\hline $\mathrm{BMI}, \mathrm{kg} / \mathrm{m}^{2}$ & $22.7 \pm 2.0$ & $25.8 \pm 2.2$ & $30.3 \pm 4.2$ & \\
\hline Age, years & $55.8 \pm 4.3$ & $56.4 \pm 4.4$ & $56.6 \pm 4.5$ & $<0.0001$ \\
\hline Annual income, USD & $47,294 \pm 34,171$ & $42,959 \pm 26,960$ & $39,026 \pm 22,727$ & $<0.0001$ \\
\hline Only primary school Edu1, n (\%) & $2,088(27.2)$ & $1,320(30.5)$ & $1,686(37.3)$ & $<0.001$ \\
\hline Minimum bachelor Edu2, n (\%) & $435(5.7)$ & $138(3.2)$ & $104(2.3)$ & $<0.001$ \\
\hline Past smoker, n (\%) & $1,776(23.1)$ & $1,042(24.1)$ & $1,181(26.2)$ & 0.001 \\
\hline Current smoker, n (\%) & $2,284(29.8)$ & $1,241(28.7)$ & $1,220(27.0)$ & 0.005 \\
\hline Sport, n (\%) & $5,189(67.7)$ & $2,730(63.2)$ & $2,450(54.3)$ & $<0.001$ \\
\hline Hypertension, n (\%) & $3,120(40.7)$ & $2,187(50.6)$ & $2,942(65.1)$ & $<0.001$ \\
\hline Diabetes mellitus, n (\%) & $66(0.9)$ & $30(0.7)$ & $146(3.2)$ & $<0.001$ \\
\hline \multirow[t]{3}{*}{ Cardio vascular disease, $\mathrm{n}(\%)$} & $172(2.2)$ & $151(3.5)$ & $214(4.7)$ & $<0.001$ \\
\hline & \multicolumn{3}{|c|}{ Male study participants } & \\
\hline & $\begin{array}{l}\text { normal WC } \\
(<94 \mathrm{~cm})\end{array}$ & $\begin{array}{l}\text { increased WC } \\
(94-101.99 \mathrm{~cm})\end{array}$ & $\begin{array}{l}\text { substantially increased WC } \\
(\geq 102 \mathrm{~cm})\end{array}$ & \\
\hline Number & 6,452 & 4,952 & 3,930 & \\
\hline $\mathrm{WC}, \mathrm{cm}$ & $87.6 \pm 4.5$ & $97.3 \pm 2.3$ & $108.8 \pm 6.7$ & \\
\hline $\mathrm{BMI}, \mathrm{kg} / \mathrm{m}^{2}$ & $24.0 \pm 1.9$ & $26.8 \pm 1.8$ & $30.6 \pm 3.1$ & \\
\hline Age, years & $55.9 \pm 4.3$ & $56.2 \pm 4.4$ & $56.5 \pm 4.5$ & $<0.0001$ \\
\hline Annual income, USD & $48,869 \pm 29,610$ & $48,496 \pm 31,985$ & $45,204 \pm 36,150$ & $<0.0001$ \\
\hline Only primary school Edu $\mathrm{u}_{1}, \mathrm{n}(\%)$ & $1,095(17.0)$ & $925(18.7)$ & $939(23.9)$ & $<0.001$ \\
\hline Minimum bachelor Edu $2, \mathrm{n}(\%)$ & $908(14.1)$ & $534(10.8)$ & $287(7.3)$ & $<0.001$ \\
\hline Past smoker, n (\%) & $1,968(30.5)$ & $1,879(37.9)$ & $1,644(41.8)$ & $<0.001$ \\
\hline Current smoker, n (\%) & $2,523(39.1)$ & $1,749(35.3)$ & $1,303(33.2)$ & $<0.001$ \\
\hline Sport, n (\%) & $3,803(58.9)$ & $2,618(52.9)$ & $1,597(40.6)$ & $<0.001$ \\
\hline Hypertension, n (\%) & $3,039(47.1)$ & $2,978(60.1)$ & $2,852(72.6)$ & $<0.001$ \\
\hline Diabetes mellitus, n (\%) & $119(1.8)$ & $102(2.1)$ & $155(3.9)$ & $<0.001$ \\
\hline Cardio vascular disease, $\mathrm{n}(\%)$ & $294(4.6)$ & $323(6.5)$ & $363(9.2)$ & $<0.001$ \\
\hline
\end{tabular}

${ }^{\mathrm{a}} \mathrm{p}$ values for overall group comparison based on F-test or $\chi^{2}$ test.
In Denmark, all public health care services are registered in various registers, and the personal identification code made it possible to collect information on all participants' use of public health care services in the 7-year follow-up period. For each study subject, we obtained the following information over the study period without any restrictions related to the medical conditions motivating the services:i) somatic in- and out-patient treatments, ii) psychiatric in- and out-patient treatments [41], iii) primary sector health care services (general practitioners, practising specialists, dentists, physiotherapists, psychologists etc.) and iv) prescription drugs entitled to a subsidy.

The Danish Case Mix System (Diagnosis Related Groups, DRG) was used to assign costs to all somatic out-patient and in-patient services provided in the period. The National Board of Health's per diem charge and ambulant charge for psychiatric treatments were used to calculate the cost of psychiatric treatment. The cost of the services of the primary health care sector was extracted from the National Health Insurance Register. We calculated the costs of drug prescription at the retail costs of each compound and dosage as of the date of purchase.

All health care costs were adjusted to 2005 price levels and aggregated at the individual level. Subsequently the mean annual health care cost per subject was calculated by dividing the total costs by the number of person years registered in the 7-year follow-up period. In the presentation of the results Danish kroner (DKK) are converted to USD (using currency rate DKK 100.- = USD 17.40).

\section{Analytical Model}

Analyses were restricted to individuals with complete responses on all variables and to those who were not characterised as underweight at baseline. This latter restriction was applied in order to simplify the model by focusing on the effects of overweight and obesity only in comparison with normal weight. Moreover, the relationship between underweight and health care costs may be characterised by reverse causality when the low body weight is due to a disease-induced weight loss. For the same reason people with a cancer diagnosis were excluded from the study. Data were analysed separately for men and women due to possible differences in effects of body size.

Linear regression was used to model the relationship between WC and mean annual health care costs. Preliminary examination indicated that the costs were characterised by a skewed distribution with a long right hand tail, as is frequently observed for cost data. Therefore the cost data were normalised by applying the logarithm to costs. Note that the application of the log of costs as the dependent variable implies that the coefficients of the model should be interpreted as the pro anno rate of increase in health care costs (in per cent).

The strategy for the analysis was to establish a simple model, which explains the association between WC and health care costs without loosing explanatory power. Therefore, based on theoretical considerations a set of different models was investigated. To account for potential variations in 
the association between costs and WC across different ranges of WC, spline functions were applied in all the models. Spline functions are piecewise continuous linear functions connected at joint points (knots) [42]. The knots were set at the WHO's cut-off points for increased and substantially increased WC. Application of spline functions instead of a simple linear function allowed the curves to change direction at the knots, and hereby allowing the relationship between $\mathrm{WC}$ and health care costs to differ across the different WC categories.

In order to test for different relationships between $\mathrm{WC}$ and health care costs for participants with and without co-morbidities, co-morbidity status at baseline was included as a potential explanatory variable, labelled 'Full model'. A participant was included in the co-morbidity group if (s)he had hypertension, diabetes or CVD. Furthermore, the model was adjusted for potential confounders identified in the literature; age, education, income, smoking habits, physical activity. The Appendix (see below) provides a more technical presentation of the models.

A 'Reduced model' (simple co-morbidity function) investigates whether the association between costs and WC differ across all ranges of WC, or whether the number of knots can be reduced. Like the 'Full model', this model was adjusted for co-morbidities and potential confounders. However, if age, education, income, smoking status and physical activity are factors, which not only contribute to explaining health care costs but also are mediating the effects of $\mathrm{WC}$, the inclusion of these variables potentially results in a biased estimate of the association between WC and health care costs. Therefore the coefficients estimate of the association between $\mathrm{WC}$ and costs were validated through comparison of the WC coefficient estimates in a model with and without inclusion of potentially confounders, labelled 'Simple model' (simple WC and co-morbidity function) and 'Simple model, no confounders' (reduced model and no confounders).

Baseline characteristics were compared across the three WC groups; Pearson's $\chi^{2}$ test (for categorical variables) or F-test (for continuous variables) were used to assess statistical significance. The significance of each partial regression coefficient was assessed using a two-sided Students $t$ test. Overall goodness of fit was measured with the coefficient of determination $\left(R^{2}\right)$. Restrictions of parameters were tested by use of likelihood ratio test. The predicted values from the log model were transformed into actual costs via application of smearing estimates [43]. Statistical analyses were performed using Stata version 9.1 (College Station, TX, USA). Due to the large sample size, statistical significance was set conservatively at $\mathrm{p}<0.01$. The study was carried out in accordance with Danish Law after permission from the Danish Data Protection Agency.

\section{Results}

\section{Population Characteristics}

Out of the total of 31,840 subjects $(15,334$ men and 16,506 women) with complete data, 1,081 subjects (679 men and 402 women) died during the observation time. Among men the number of dead participants differed significantly across the WC categories $(\mathrm{p}<0.001)$, while the difference was not significant for the women $(p=0.228)$.

\section{Descriptive Results}

Table 1 shows baseline characteristics of the subjects by categories of WC. Participants with increased or substantially increased WC were more likely to have co-morbidities (hyper- tension, diabetes and CVD) than participants with normal WC. The results suggest that there is a range of confounders that should be controlled for when aiming to assess the putative causal relationship between $\mathrm{WC}$ and costs.

The results of the 'Simple model' and the 'Simple model, no confounders' are reported in table 2, while the 'Full model' and the 'Reduced model' are reported in table 3 . Analyses of the co-morbidity interaction in the WC-cost association show that the co-morbidity interaction terms were statistically insignificant, individually and jointly ('Full model'; table 3). Likelihood ratio test showed that omission of the co-morbidity interaction terms was acceptable ( $\mathrm{p}=0.25$ for women, $\mathrm{p}=0.26$ for men). In addition, equal slope of the WC-cost association in the entire WC-range above normal WC, and no association in the normal WC range were found ('Reduced model'; table 3). The 'Simple model' includes only one WC variable, reflecting the association between centimetres above normal WC range and costs (table 2). The likelihood ratio test showed that these restrictions were acceptable ( $p=0.06$ for women, $\mathrm{p}=0.19$ for men).

The 'Simple model' shows a highly statistically significant association between health care costs and WC for individuals above normal WC range, and significant co-variates. In order to validate the coefficient estimate of the association between WC and costs reported in the 'Simple model', we excluded the co-variates in the 'Simple model, no confounders'. Comparison of 'Simple model' and 'Simple model, no confounders' shows that the WC-cost association is relatively unaffected by exclusion of the additional explanatory variables. This suggests that the confounder-mediator problem is of minor relevance in the present analysis.

The result of the 'Simple model, no confounders' implies that for women an increased WC will incur a pro anno additional cost of $1.25 \%$ for every added centimetre above $80 \mathrm{~cm}$ WC. For men the impact is even larger, at $2.08 \%$ per centimetre above $94 \mathrm{~cm}$ WC.

For a better understanding of the magnitude of change, the smearing estimate was used to transform the estimated coefficients back into USD. Figure 1 shows the predicted annual costs of health care for men and women, with and without comorbidities in relation to the range of WC. The estimates are based on the coefficient reported in 'Simple model, no confounders', since this estimate allows for a simple exposition of the results, as seen in figure 1. Figure 1 shows that the costs for every added centimetre above the normal range is higher for people with co-morbidities than for people without. Note that although we found no statistically significant impact of having co-morbidities on the rate of increased health care costs per centimetre, the actual increase in future health care costs is larger for those people with at least one co-morbidity because the general level of health care costs is higher for this group irrespective of WC.

The average annual cost of health care for a woman without co-morbidities and with a normal waistline is approximately 
Table 2. Results of the multiple regression analyses of the relationship between WC and log mean annual health care costs, adjusting for potential confounders*

\begin{tabular}{|c|c|c|c|c|c|c|c|c|c|c|c|c|}
\hline Parameter & $\begin{array}{l}\text { Inter- } \\
\text { cept }\end{array}$ & $\begin{array}{l}\text { Centi- } \\
\text { metre } \\
\text { above } \\
\text { normal } \\
\text { WC }\end{array}$ & $\begin{array}{l}\text { Co- } \\
\text { morb }^{a}\end{array}$ & $\begin{array}{l}\text { Age, } \\
\text { years }\end{array}$ & $\mathrm{Edu}_{1}^{\mathrm{b}}$ & $\mathrm{Edu}_{2}{ }^{\mathrm{c}}$ & $\begin{array}{l}\text { Income, } \\
\text { USD }\end{array}$ & Sport & $\begin{array}{l}\text { Past } \\
\text { smo- } \\
\text { kers }\end{array}$ & $\begin{array}{l}\text { Current } \\
\text { smo- } \\
\text { kers }\end{array}$ & $\begin{array}{l}\text { Heavy } \\
\text { smo- } \\
\text { kers }\end{array}$ & $\mathrm{R}^{2}$ \\
\hline \multicolumn{13}{|l|}{ Simple model } \\
\hline \multicolumn{13}{|l|}{ Women } \\
\hline Parameter estimates & 5.51 & 0.0125 & 0.1750 & 0.0250 & 0.0342 & 0.0112 & $-8.38 \mathrm{e}-07$ & 0.0101 & 0.1174 & 0.1918 & 0.1496 & 0.0538 \\
\hline $\mathrm{p}$ value & 0.000 & 0.000 & 0.000 & 0.000 & 0.049 & 0.772 & 0.001 & 0.542 & 0.000 & 0.000 & 0.000 & \\
\hline \multicolumn{13}{|l|}{ Men } \\
\hline Parameter estimates & 3.77 & 0.0208 & 0.2569 & 0.0508 & -0.0039 & -0.0648 & $-4.19 \mathrm{e}-07$ & -0.0515 & 0.1449 & 0.2325 & 0.0833 & 0.0906 \\
\hline $\mathrm{p}$ value & 0.000 & 0.000 & 0.000 & 0.000 & 0.879 & 0.019 & 0.158 & 0.007 & 0.000 & 0.000 & 0.012 & \\
\hline \multicolumn{13}{|c|}{ Simple model, no confounders } \\
\hline \multicolumn{13}{|l|}{ Women } \\
\hline Parameter estimates & 6.96 & 0.0132 & 0.2120 & & & & & & & & & 0.0281 \\
\hline $\mathrm{p}$ value & 0.000 & 0.000 & 0.000 & & & & & & & & & \\
\hline \multicolumn{13}{|l|}{ Men } \\
\hline Parameter estimates & 6.68 & 0.0218 & 0.3376 & & & & & & & & & 0.0430 \\
\hline $\mathrm{p}$ value & 0.000 & 0.000 & 0.000 & & & & & & & & & \\
\hline
\end{tabular}

*Note that the units of the variables differ, and therefore the coefficient estimates cannot be directly compared.

${ }^{a}$ Co-morb is a dummy variable which represents membership of the co-morbidity group.

${ }^{b} E_{u_{1}}$ is a dummy variable indicating $\leq 10$ years of schooling.

${ }^{c} \mathrm{Edu}_{2}$ is a dummy variable indicating that the respondent had a university degree.

USD 1,814.-, while the future annual costs of health care is approximately USD 2,242.- if she has co-morbidities. The average annual future costs of health care for a woman without co-morbidities and a WC of $85 \mathrm{~cm}$ and $95 \mathrm{~cm}$ are approximately USD 1,938- and USD 2,211.-, respectively. This implies that a woman with a waistline of $95 \mathrm{~cm}$ and without comorbidities can be expected to incur added future costs of approximately USD 397.- per annum compared to a woman in the normal WC group, corresponding to $22 \%$ higher health care costs. For a woman with co-morbidities the extra cost would be approximately USD 491.- per annum. For a man without co-morbidities an increase of the WC from normal values to $109 \mathrm{~cm}$ corresponds to an increase in health care costs of $39 \%$.

\section{Discussion}

In this study, we examined the relationship between WC, as a strong marker of the adverse health implications of obesity, and future health care costs over a 7-year period, and we found the excess health care costs associated with increased WC to be substantial. We found that women with increased or substantially increased WC had $1.25 \%$ higher annual health care costs per centimetre above normal WC, whereas men with increased or substantially increased WC had $2.08 \%$ higher annual health care costs per centimetre above normal WC. Our results are in accordance with previous studies that have shown a positive association between obesity and health care costs $[5,11,17,23,44]$. However, as noted in the introduction, most previous studies of the relationship between obesity status and health care costs have analysed the association between health care costs and BMI. Hence, it is not possible to directly compare the results of the present study with previous evidence from the literature.

In Denmark total expenditure on health care constituted $9.1 \%$ of gross domestic product (GDP) in 2005. For comparison in the USA and in the UK these figures were 15.3 and $8.3 \%$, respectively [45].

Two studies have used WC as measurement for obesity [10, 12]. The first study [10] found that the highest WC quartile was associated with significantly higher mean total costs than the other quartiles, while the second study [12] found that the mean hospital costs over an observation period of 3 years were $38.8 \%$ higher among obese women and $45.3 \%$ higher among obese men (obesity was defined in this study as a WC $\geq 102 \mathrm{~cm}$ for men or $\geq 88 \mathrm{~cm}$ for women). The differences in costs were not statistically significant. However, as mentioned in the introduction these studies have some weaknesses in their designs. 


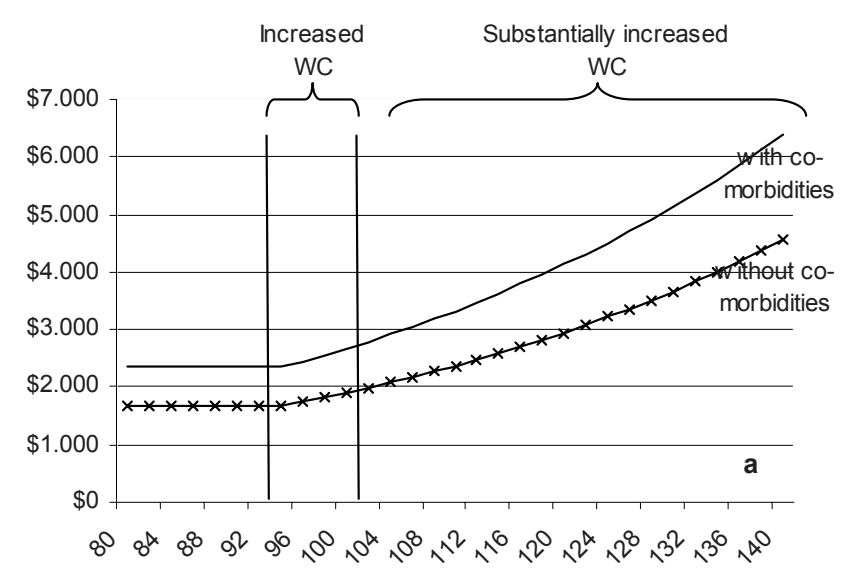

WC

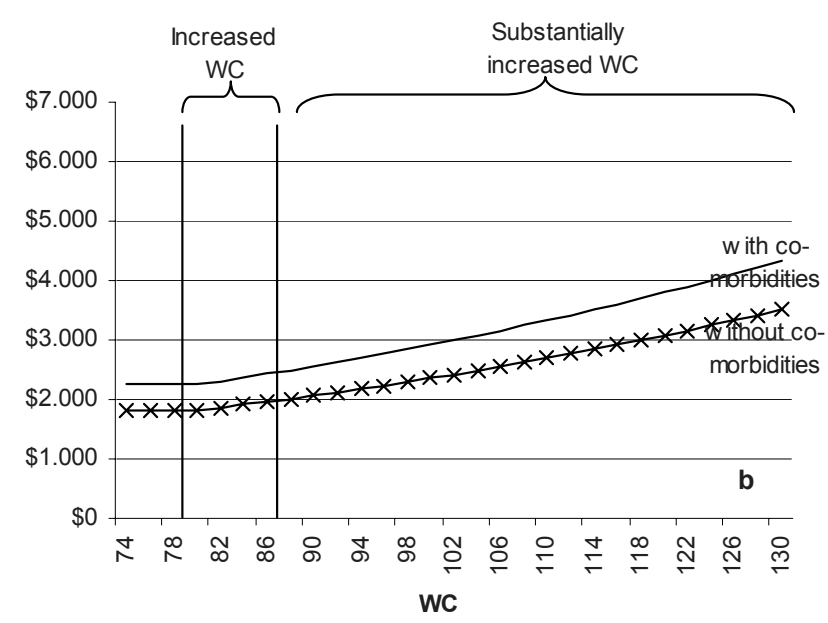

Fig. 1. Predicted annual health care cost (USD) by waist circumference (WC), estimated on the basis of the 'Simple model, no confounders'. a Men, b women.

Like Folmann et al. [12] we found that the association between WC and health care costs is greater for obese men. Reasons for these observed gender differences in the association between WC and health care costs can be that the increase in size of the visceral fat mass for a given change in $\mathrm{WC}$ is smaller among women.

Although the rate of increase in health care costs per added centimetre above normal WC is similar for individuals with and without co-morbidities, it should be noted that the absolute increase in costs as WC increases is higher for individuals with co-morbidities due to their general higher level of costs amongst those individuals (indicated by the statistically significant co-morbidity variable, see table 2).

To strengthen our analyses, we adjusted for several confounders including age, education, income, smoking status and status of physical activity. We found no appreciable effects of including these variables on the estimated rate of increase in health care costs incurred by an increased WC, which indicates that our results are robust and not potentially affected by the difficulties associated with the confounder-mediator distinction. In addition, it should be noted that the coefficients of the potential confounders were as expected, which can be regarded as a validation of the data.

Our study has several methodological advantages. First, the analyses were based on follow-up data of a large number of subjects $(\mathrm{n}=31,840)$. Second, individual data on health care consumption and associated costs were extracted from valid registers, and the consumption of health care services could be directly linked with personal details for the single individual. Third, the WC measurements have high validity as they were measured by trained staff. Fourth, the impact of WC upon health care costs was analysed after adjustment of a variety of potential confounders. Fifth, in the sample selection process potential sources of bias and confounding due to illness-related weight losses were sought to be eliminated by exclusion of people with a history of cancer and people with a BMI $<18.5 \mathrm{~kg} / \mathrm{m}^{2}$.

Nevertheless, the present study is not without limitations. There is a risk of selection bias, since only one third (35\%) of the invited individuals participated in this study. The selection bias is especially expected to exist in the co-morbidity group since it is likely that it is the healthier fraction of those with co-morbidities who choose to participate in a study such as this one. However this may not affect the strength of the association between levels of observed WC and subsequent costs. Also, the white-coat problem for blood pressure measurement means that some people may wrongly have been allocated to the co-morbidity group. There is no obvious reason to believe that the cost estimates associated with $\mathrm{WC}$ for given categories of co-morbidity is biased. The restricted age group (age at baseline $=50-64$ years) limit for extrapolating to the general population.

Our analysis was limited to health care costs and, therefore, does not address other costs resulting from obesity. Previous studies have shown that obesity is associated with absenteeism [46-48], unemployment [49], social stigmatization and discrimination [50] etc. Finally, the study design addressed only interindividual WC differences, and not intra-individual WC changes before and after the baseline assessment on health care costs. Hence, one should be cautious in extrapolating the results observed in this study to a setting, which involves intraindividual WC changes.

The likelihood that the observed association between future health care costs and WC at baseline reflects a causal relationship is strengthened by the fact that the association was unaffected by inclusion of alternative explanatory factors. Causality does, however, not imply reversibility. The question of whether a decrease in WC can induce reduction in future health care costs can only be answered through application of a longitudinal observational or interventional study design with repeated WC measurements over time. However, for those individuals who are healthy at baseline increased WC 


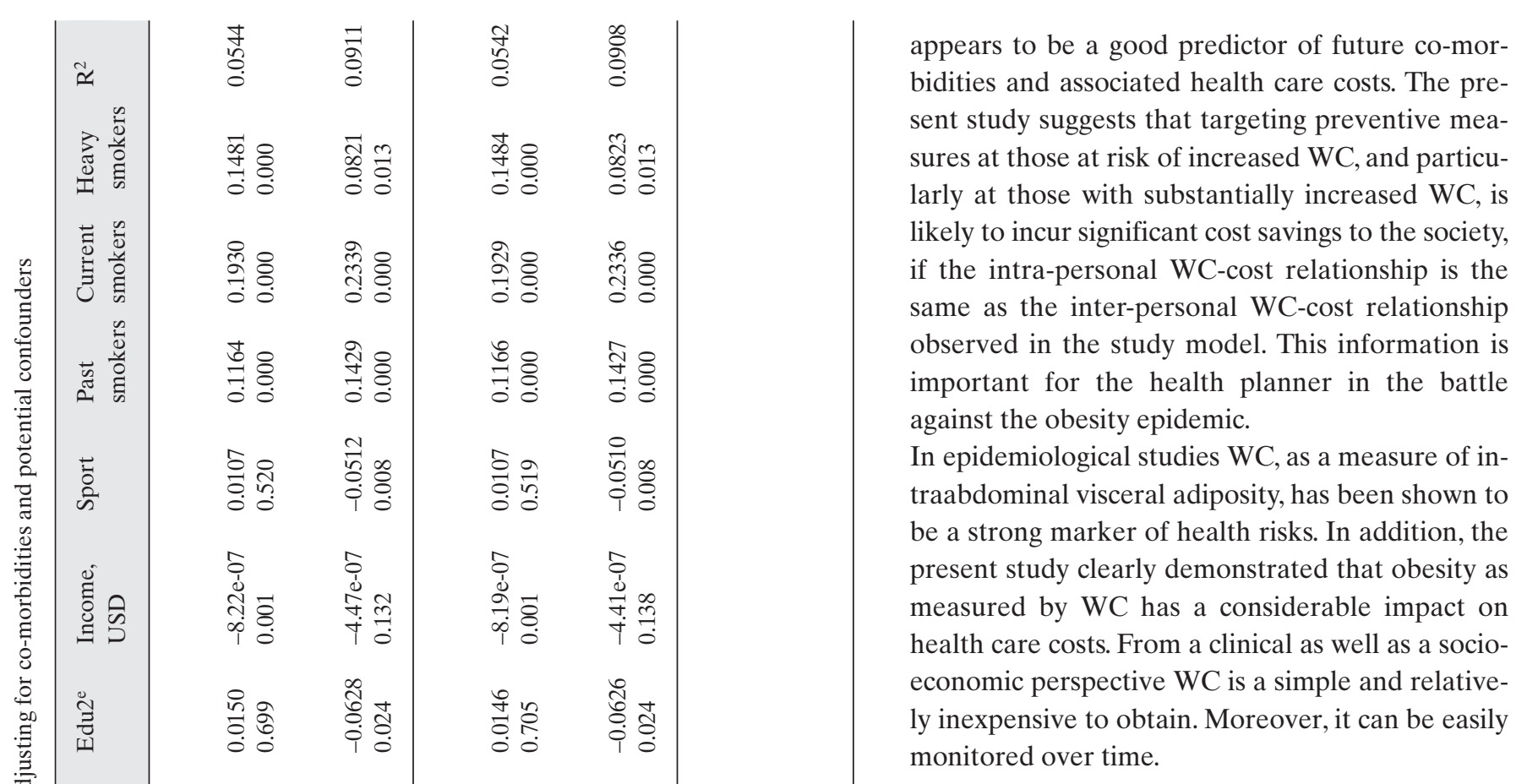

\section{Conclusions}

In conclusion, our results indicate that future health care costs are higher for persons who has an increased or substantially increased WC than for individuals with normal WC. For women and men with increased or substantially increased WC health care costs rise at a rate of 1.25 and $2.08 \%$, respectively, per added centimetre above normal waistline. These results suggest that there may be a potential for significant resource savings through prevention of abdominal obesity.

\section{Appendix}

Ordinary least square regression was used to model the relationship between WC and mean annual health care costs. As with a long right hand tail, the distribution of residuals were normalised by applying the logarithm to costs. Hereafter the kurtosis was 3.876 and the skewness was 0.137 (for a normal distribution the kurtosis is 3 and the skewness is 0 ).

The effect of WC on health care cost was modeled as a linear spline function. The applied basis model ('Full model') has the following structure:

$$
\begin{aligned}
& \log (\operatorname{cost})=\beta_{1}+\beta_{2} \mathrm{WC}+\delta_{1} \mathrm{~d}_{1}\left(\mathrm{WC}-\mathrm{x}_{1}\right)+\delta_{2} \mathrm{~d}_{2}\left(\mathrm{WC}-\mathrm{x}_{2}\right) \\
& +\delta_{3} \mathrm{Co}+\delta_{4} \mathrm{CO} \times \mathrm{WC}+\delta_{5} \mathrm{Co} \times \mathrm{d}_{2}\left(\mathrm{WC}-\mathrm{x}_{1}\right)+\delta_{6} \mathrm{Co} \times \mathrm{d}_{2} \\
& \left(\mathrm{WC}-\mathrm{x}_{2}\right)+\mathrm{a}_{1} \mathrm{Z}_{1}
\end{aligned}
$$

where $W C$ is waist circumference, $d_{1}$ and $d_{2}$ are dummy variables, indicating whether a person has increased $\left(d_{1}=1\right.$ and $\left.d_{2}=0\right)$ and substantially increased $\mathrm{WC}\left(d_{1}=1\right.$ and $\left.d_{2}=1\right)$. The knots of WC were for women set to $80 \mathrm{~cm}\left(\mathrm{x}_{1}\right)$ and 88 the cost data were characterised by a skewed distribution 
$\mathrm{cm}\left(\mathrm{x}_{2}\right)$ and for men to $94 \mathrm{~cm}\left(\mathrm{x}_{1}\right)$ and $102 \mathrm{~cm}\left(\mathrm{x}_{2}\right)$. Co is a dummy variable which represents membership of the co-morbidity group ( $=1$ if participant suffers from a co-morbidity; else zero), and $Z$ is a vector of potential confounders. Interaction terms test for differences in the impact of WC on costs for those with and without co-morbidities.

The potential confounders constitute of age (a continuous variable), education represented by two dummy variables $\left(E d u_{1}=1\right.$ if level of education $\leq 10$ years of schooling (else zero) and $E d u_{2}=1$ if the respondent had a university degree, else zero), income (a continuous variable), smoking habits represented by three dummy variables (current smokers, past smokers and heavy smokers), physical activity (one dummy variable). In all, four models were made. The statistical properties of each model were systematically assessed. Furthermore, the residuals were analysed in order to asses whether the distributional assumptions of OLS regression were met. In the presence of heteroscedasticity, White-corrected standard errors were used and reported. Restrictions of parameters were tested by use of likelihood ratio test. The two primary models are shown in table 2 , whereas the results of the 'Full model' and the 'Reduced model' are shown in table 3 .

\section{Sources of Funding}

This study was financed by Sanofi Aventis. The views expressed are solely those of the authors.

\section{Disclosures}

Dorte Gyrd-Hansen and Thorkild I.A. Sørensen were members of the former Advisory Board of Sanofi Aventis, Denmark. Thorkild I.A. Sørensen is currently collaborating with Nestlé Research Centre, Lausanne, and DSM, The Netherlands, on obesity research. The other authors report no disclosures.

\section{Acknowledgements}

We would like to thank the Danish Cancer Society for given access to data of the Diet, Cancer and Health study.

\section{References}

1 WHO: Obesity: preventing and managing the global epidemic. Report of a WHO consultation. World Health Organ Tech Rep Ser 2000;894:i-xii, 1.

2 Haslam DW, James WPT: Obesity. Lancet 2005; 366:1197-1209.

3 Finkelstein EA, Fiebelkorn IC, Wang G: National medical spending attributable to overweight anc obesity: how much, and who's paying? Health Aff (Millwood) 2003;Suppl Web Exclusives(Millwood 2003 Jan-Jun Suppl Web Exclusives):W3-219.

4 Finkelstein EA, Fiebelkorn IC, Wang G: State-level estimates of annual medical expenditures attributable to obesity. Obes Res 2004;12:18-24.

5 Andreyeva T, Sturm R, Ringel JS: Moderate and severe obesity have large differences in health care costs. Obes Res 2004;12:1936-1943.

6 Arterburn DE, Maciejewski ML, Tsevat J: Impact of morbid obesity on medical expenditures in adults. Int J Obes (Lond) 2005;29:334-339.

7 Birmingham CL, Muller JL, Palepu A, Spinelli JJ, Anis AH: The cost of obesity in Canada. CMAJ 1999:160:483-488.

8 Colditz GA: Economic costs of obesity. Am J Clin Nutr 1992;55(2 suppl):503S-507S.

9 Colditz GA: Economic costs of obesity and inactivity. Med Sci Sports Exerc 1999;31(11 suppl):S663S667.

10 Cornier M-A, Tate CW, Grunwald GK, Bessesen DH: Relationship between waist circumference, body mass index, and medical care costs. Obes Res 2002;10:1167-1172.

11 Daviglus ML, Liu K, Yan LL, Pirzada A, Manheim L, Manning W, Garside DB, Wang R, Dyer AR, Greenland P, Stamler J: Relation of body mass index in young adulthood and middle age to Medicare expenditures in older age. JAMA 2004 292:2743-2749.

12 Folmann NB, Bossen KS, Willaing I, Sørensen J, Andersen JS, Ladelund S, Jørgensen T: Obesity, hospital services use and costs; in Bolin K, Cawley J (eds): The Economics of Obesity. Amsterdam, Elsevier, 2007, pp 319-332.

13 Gorsky RD, Pamuk E, Williamson DF, Shaffer PA, Koplan JP: The 25-year health care costs of women who remain overweight after 40 years of age. Am J Prev Med 1996;12:388-394.
14 Katzmarzyk PT, Janssen I: The economic costs associated with physical inactivity and obesity in Canada: an update. Can J Appl Physiol 2004;29:90-115.

15 Kuriyama S, Tsuji I, Ohkubo T, Anzai Y, Takahashi K, Watanabe Y, Nishino Y, Hisamichi S: Medical care expenditure associated with body mass index in Japan: the Ohsaki Study. Int J Obes Relat Metab Disord 2002;26:1069-1074.

16 Levy E, Levy P, Le Pen C, Basdevant A: The economic cost of obesity: the French situation. Int J Obes Relat Metab Disord 1995;19:788-792.

17 Pronk NP, Goodman MJ, O'Connor PJ, Martinson BC: Relationship between modifiable health risks and short-term health care charges. JAMA 1999; 282:2235-2239.

18 Schmid A, Schneider H, Golay A, Keller U: Economic burden of obesity and its comorbidities in Switzerland. Soz Präventivmed 2005;50:87-94.

19 Segal L, Carter R, Zimmet P: The cost of obesity: the Australian perspective. Pharmacoeconomics 1994;5(suppl 1):45-52.

20 Swinburn B, Ashton T, Gillespie J, Cox B, Menon A, Simmons D, Birkbeck J: Health care costs of obesity in New Zealand. Int J Obes Relat Metab Disord 1997;21:891-896.

21 Thompson D, Edelsberg J, Kinsey KL, Oster G: Estimated economic costs of obesity to U.S. business. Am J Health Promot 1998;13:120-127.

22 Thompson D, Edelsberg J, Colditz GA, Bird AP, Oster G: Lifetime health and economic consequences of obesity. Arch Intern Med 1999;159: 2177-2183.

23 Thompson D, Brown JB, Nichols GA, Elmer PJ, Oster G: Body mass index and future healthcare costs: a retrospective cohort study. Obes Res 2001;9:210-218.

24 Tucker LA, Clegg AG: Differences in health care costs and utilization among adults with selected lifestyle-related risk factors. Am J Health Promot 2002;16:225-233.

25 Wee CC, Phillips RS, Legedza AT, Davis RB, Soukup JR, Colditz GA, Hamel MB: Health care expenditures associated with overweight and obesity among US adults: importance of age and race. Am J Public Health 2005;95:159-165.

26 Wolf AM, Colditz GA: The cost of obesity: the US perspective. Pharmacoeconomics 1994;5(suppl 1): 34-37.
27 Wolf AM, Colditz GA: Current estimates of the economic cost of obesity in the United States. Obes Res 1998;6:97-106.

28 van Baal PHM, Polder JJ, de Wit GA, Hoogenween RT, Feenstra TL, Boshuizen HC, Engelfriet PM, Brouwer WBF: Lifetime medical costs of obesity: prevention no cure for increasing health expenditure. PLoS Medicine 2008;5:242-249.

29 Buescher PA, Whitmire T, Plescia M: Relatinship Between body mass index and medical care expenditures for North Carolina adolescents enrolled in Medicaid in 2004. Prev Chronic Dis 2008;5:A04.

30 Quesenberry CP, Caan B, Jacobson A: Obesity, health services use, and health care costs among members of a health maintenance organization. Arch Intern Med 1998;158:466-472.

31 Raebel MA, Malone DC, Conner DA, Xu S, Porter JA, Lanty FA: Health services use and health care costs of obese and nonobese individuals. Arch Intern Med 2004;164:2135-2140.

32 Bigaard JV: Fat distribution an dall-cause mortality. $\mathrm{PhD}$ thesis, Copenhagen University Hospital, 2004.

33 Seidell JC, Deurenberg P, Hautvast JGAJ: Obesity and fat distribution in relation to health - current insights and recommendations. World Rev Nutr Diet 1987;50:57-91.

34 Lean MEJ, Han TS, Morriison CE: Waist circumference as a measure for indicating need for weight management. BMJ 1995:311:158-161.

35 Poulio MC, Despres JP, Lemieux S, Moorjani S, Bouchard C, Tremblay A, Nadeau A, Lupien PJ: Waist circumference and abdominal sagittal diameter: best simple anthropometric indexes of abdominal visceral adipose tissue accumulation and related cardiovascular risk in men and women. Am J Cardiol 1994;73:460-468.

36 Rankinen T, Kim SY, Perusse L, Despres JP, Bouchard C: The prediction of abdominal visceral fat level from body composition and anthropometry: ROC analysis. Int J Obes Relat Metab Disord 1999;23:801-809.

37 Chan DC, Watts GF, Barett PHR, Burke V: Waist circumference, waist-to-hip ratio and body mass index as predictors of adipose tissue compartments in men. QJM 2003;96:441-447. 
38 Højgaard B, Gyrd-Hansen D, Olsen KR, Søgaard J, Sørensen TIA: Waist circumference and body mas index as predictors of health care costs. Submitted to Plos One 2008

39 Ross R, Berentzen T, Bradshaw AJ, Janssen I, Kahn HS, Katzmarzyk PT, Kuk JL, Seidell JC, Snijder MB, Sørensen TIA, Despres JP: Does the relatinship between waist circumference, morbidity and mortality depend on measurement protocol for waist circumfrence? Obes Rev 2007;DOI: 10.1111/j. 1467-789x.2007.00411.x.

40 Tjønneland AM, Overvad OK: Diet, cancer and health a prospective cohort study and biological bank in Denmark (in Danish). Ugeskr Laeger 2000; 162:350-354.
41 Munk-Jorgensen P, Mortensen PB: The Danish Psychiatric Central Register. Dan Med Bull 1997; 44:82-84.

42 Greene WH: Econometric Analysis, 5th ed. Upper Saddle River, Prentice Hall, 2003.

43 Duan N: Smearing estimate: A nonparametric retransformation method. J Am Stat Assoc 1983;78: 605-610.

44 Heithoff KA, Cuffel BJ, Kennedy S, Petrelli JM: The association between body mass and health care expenditures. Clin Ther 1997;19:811-820.

45 OECD: 2007.

46 Bungum T, Satterwhite M, Jackson AW, Morrow JR: The relationship of body mass index, medical costs, and job absenteeism. Am J Health Behav 2003;27:456-462.
47 Narbro K, Johnsson E, Larsson B, Waaler H, Wedel $\mathrm{H}$, Sjöström L: Economic consequences of sickleave and early retirement in obese Swedish women. Int J Obes 1996;20:895-903.

48 Morris S: Body mass index and occupational attainment. J Health Econ 2006;25:347-364.

49 Sarlio-Lähteenkorva S, Lahelma E: The association of body mass index with social and economic disadvantage in women and men. Int J Epidemiol 1999; 28:445-449.

50 Puhl R, Brownell KD: Bias, discrimination, and obesity. Obes Res 2001;9:788-805. 